\title{
Leaning Out in Higher Education: A Structural, Postcolonial Perspective
}

\section{Liz Jackson}

A new kind of gender equality ideology is rising in popularity, particularly in western societies. Though feminists can no doubt be pleased that this latest movement foregrounds the importance of gender equality for the next generation, this new ideology conceives feminism in a pragmatic and simplistic way, reframing it to be nonthreatening to the status quo. In the political domain, the United Nations He-For-She initiative appeals to men and women inclusively to fight for greater gender equity, emphasizing equity as valuable and beneficial to both parties, and placing men as central players. In popular culture, actress and comedienne Amy Poehler’s (2015) Smart Girls campaign encourages young people (not just girls) to “change the world by being yourself,” an inoffensive, seemingly easy way to embrace gender equality. And in the economic sphere, Sheryl Sandberg's Lean In: Women, Work, and the Will to Lead (2013) articulates a "sort of a feminist manifesto," by a self-identified "pom-pom girl for feminism”: a cheery woman who wants to guide women to succeed more equally with men in the workplace (p. 9; p. 158).

"Lean In” has become a significant movement within this new feminist landscape. It has expanded from one book to two, and from an American viewpoint to a global one, partnering with dozens of multinational corporations and nongovernmental organizations worldwide. Its guidance for women has reverberated in discourses in the non-profit and start-up worlds (Shevinsky, 2015), in the arts, sports, and more (Kay \& Shipman, 2014). However there are some limitations of the kind of feminist thinking exemplified by Lean In. This essay critically examines the implications of Lean In as a rising discourse or ideology in relation to higher education within and outside western societies. I offer three major criticisms. The first is that Sandberg (among others) offers a deficiency model of gender equality that partly blames women for sexism by focusing on internal rather than external change. Second, such emerging discourses tend to essentialize gender, precluding substantive recognition of intersectionality. Third, it is not easy to translate the pragmatic advice given to women across national contexts, as Lean In and related discourses reflect particular cultural conceptions of the workplace. I elaborate these claims and their implications in higher education in this essay. 


\section{Not a Girl, Not Yet a Man}

Although Lean In online has featured a section on tips for men (2016), acknowledging, as HeFor-She does, that men do play a role in this “man’s world” and in enhancing gender equity, Lean In has as its main focus the inner mental, emotional, and psychological world and habits of women, as individuals. Sandberg justifies this focus by elaborating a "chicken-and-egg situation.” The chicken is women's insecurity, learned and deeply engrained; the egg is external barriers: the world around us, including discriminatory forces. She expresses vague support for those who care about the egg, but is herself primarily “encouraging women to address the chicken” (2013, p. 9). This is an attractive message. An image is given that is simple and clear: a woman leans forward at a conference room table that is otherwise presumably dominated by men, and expresses an idea or challenge, instead of just thinking about it and waiting for someone else to say it. Instead of going with the flow, she becomes with this proactive gesture a person of action and a constructive team player, and she is thus less likely to be casually dismissed in the future, as unresponsive or as less committed than her more vocal and aggressive male counterparts. By making this simple act a habit, women can become and be seen, through their own actions, as of more equal value alongside men in the workplace.

This symbolic gesture of leaning in also reflects the interlocking individualistic, pragmatic, and assimilationist values embedded in the mainstream ideology of the American Dream (which intersects with global neoliberal ideology as well, as I discuss later). First, the message is individualistic. The problem is not something foggy, structural, or complicated, “out there”. It may be true that some men favor other men over women in a prejudiced way in the workplace, but changing other people is not Sandberg's primary mission. What you can change is you! If each woman as an individual develops and functions as men do, as model employees who are proactive and confident, women can at least break the "internal barrier" of the chicken-and-egg problem of inequality. This view is also pragmatic, and easy to follow: Though there are some murky inner workings of the mind that Sandberg acknowledges play a role in women's habits, you can help yourself by doing something that can easily be understood: speak up, lean in, be assertive. The message is to not worry about what 
scholars and sociologists think (Sandberg distances herself from these people) but to focus on what you can easily understand how to do.

Finally the message is assimilationist. In not dealing with what Sandberg calls the egg (the outside world), the message is unthreatening within a status quo wherein notions of institutional bias and structural inequality remain contested and are seen as threatening to those who identify as advantaged in society (Jackson, 2014a). In corporate America, as in the western public sphere and higher education contexts, the idea that sexism (and other oppressions like racism) continues to exist is often met with protest by those thinking in individualistic terms: "How can sexism play a role when I as a man worked hard for what I achieved, and when I did not discriminate against, or act prejudiced toward, any women?” Interlocking with a pragmatic view, the world of work is one where many people must “pull themselves up by their bootstraps.” Few people received “free rides” after all, so the story goes. Some women (and people of color) have done it, so surely all others, who really try, can do it too (Hytten and Warren, 2003).

In not challenging the status quo or external environment, the problem is thus attributed to individuals who can and should assimilate to the dominant values of the workplace, those associated with its leadership: men. Women are therefore encouraged to think and be more like men to get ahead, regardless of documented unequal treatment which is unrelated to women's “failure” to lean in (which Sandberg also acknowledges). In this model, women are, in a sense, deficiently men; they lack the qualities that men typically or ideally have, which apparently contribute to their greater success in the workplace. The problem here is that women are by implication blamed for behaviors which might alternatively be seen as reasonable and self-interested, if blame for inequity were passed around more equitably, and the environmental challenges that women unevenly face were more adequately considered. For evidence suggests the external world does not always bend to women who act assertively and with confidence. Successful and assertive men are better liked in workplaces than woman counterparts, as Sandberg acknowledges. This makes it easier for men to act in an ambitious, aggressive way than women at work. Women meanwhile walk a tightrope line to be ambitious without being perceived as pushy, selfish, or overly bold, as they are still often judged against gendered expectations of nurturance, softness, and sensitivity (Heilman \& Okimoto, 2007; Biernat, 
Tocci \& Williams, 2012). In this context, Lean In socialization encourages women to change their habits to be like men, but ultimately relatively unattractive and unpopular men, as they are nonetheless still perceived differently and problematically.

Such discourses can clearly be seen to intersect with those on workplace equity in other domains beyond the corporate sector. In higher education we similarly find that an individualistic, pragmatic, and assimilatory discourse is prominent today. As Sarah Aiston (2011) notes, the ideal of meritocracy, wherein individuals compete presumably equally for success according to universally held professional standards, is primary in higher education contexts experienced by women academics. Individualization here is promoted, as the act of focusing on the self for solutions, even to “systematic contradictions” (Aiston, 2011, p. 281). Yet women continue to experience challenges related to being seen as "other" in producing knowledge and in responding to academic expectations to demonstrate assertiveness, confidence, and the like, which still appear as relatively unattractive and unlikeable features in academic women.

Thus, women in higher education face a more challenging set of expectations from students and colleagues than men, despite the continued reliance on meritocratic norms. Though they may work to be like high-achieving men, women academics are less likely to be received positively in comparison with men for doing so. Findings have been reported, time and again and across national contexts, in student evaluations of teachers in higher education, that teachers identified as women (who might even be men teaching an online course!) are more likely to be perceived as selfish, if they do not mark students work and respond to student messages more quickly than men (Boring, Ottoboni \& Stark, 2016; MacNell, Driscoll \& Hunt, 2014). Men, on the other hand, are recognized for their teaching efforts more frequently than women in equivalent settings (Boring, Ottoboni \& Stark, 2016). Positive student evaluations are unlikely to emphasize women's intelligence compared to men's, but rather suggest that students expect woman educators to be kind, nurturing, and motherly. As these evaluations have an increasingly important role in promotion of academics, these findings suggest an unequitable environment for women academics (Boring, Ottoboni \& Stark, 2016).

Outside the classroom in higher education, as in corporate workplaces, women are more likely to be recognized by higher-ups for achievements which are sociable and service-oriented, as 
they face competing pressures to be likable and ambitious, which are seen as complementary features in male scholars. Women are more likely to be commended for teaching than research in higher education environments where research is prized; they are often asked to contribute more to teaching and service than men, while being expected at the same time to do the same amount of research as men (Aiston, 2011; Misra, et al., 2011). As in the corporate sector, studies indicate that in higher education employment and salary negotiating women are less successful than men (Bowles, Babcock, \& Lai, 2007; Curtis, 2010). Though Lean In suggests that women should think and act like they deserve as much as men, Sandberg also concedes that women who come to the bargaining table in the way that men are advised to may face problems; in higher education, they have job offers rescinded, as women are still not expected to act "like men” by negotiating on their own behalves (Flaherty, 2014). It appears that people in positions of power do not equally want to work with or hire men and women who similarly negotiate for and indicate a commitment to their own self-interest and professional development.

From this perspective, the individualistic, assimilatory ideology of the workplace endorsed by Sandberg and observed also in higher education appears to blame the victim of sexism, by not recognizing how professional norms can be seen to systematically exclude women regardless of the extent to which they lean in, as leaning in fails to account for different workplace expectations still entrenched based on gender norms, of nurturing and serving others versus asserting authority and competency. Women at work, in the corporate or higher education domains, cannot win simply by emulating traits associated as masculine which have dominated the environments historically. They may not receive the same credit for the same service as men, by students or peers; they may appear selfish where men appear rational or intelligent in acting assertively and authoritatively. In education, women should not be held responsible for gender inequality challenges that they cannot resolve single-handedly. Thus it is encouraging to see He-For-She being implemented in higher education, affirming that women cannot resolve gender inequity by themselves in historically male-dominated environments. In terms of the hidden curriculum of higher education, young women should not be encouraged simply to lean in and view gender inequality as a personal problem, and He-For-She also 
thus encourages men and women students and academics to see the status quo as imperfect, not as untouchable.

Finally, a deficiency mentality about ideal gender performances in education can also be seen to reflect an overestimate of the value of particular characteristics associated with attractiveness in men but not in women. Viewing the individualistic, masculine-associated values of higher education, such as competitiveness, assertiveness, argumentativeness, independence, and rationality, as culturally embedded, we can identify instances in which these values may be problematic rather than helpful. Thus while Sandberg invites women at work to lean in, Quiet (Cain, 2013) acknowledges that some forms of creativity, collaboration, and innovation are precluded when environments privilege those who are fast on their feet, personally defensive, and aggressive, over more reflective, subtle, introverted, and/or communitarian individuals. Rather than assimilating to the norms associated with success in historically male-dominated domains, women could potentially play a role in altering these spaces for the better, not by changing themselves but by revisioning the ideal work environment. Social settings should not arbitrarily foreclose the possibility of the group or community benefiting from the lessons of those who are not always the first to speak or the loudest. As conference room priorities do not always require fast or competitive communication, preparing people for discussions in advance, so reflection can take place, and offering multiple venues for people to communicate their ideas can be ways to not exclude or diminish the potential and contributions of those who are not quick to lean in.

On the other hand, a highly simplistic imaginary of gender essentialism is also at work in assimilatory, individualistic discourses of women at work, in Lean In and higher education. The variety of human expressions and ways of being is dichotomized in a deficiency view as a simplistic gender binary, despite the fact that variety and diversity mark both women and men’s identities and styles of self-expression across workplaces and cultures. By implication of the binary, as He-For-She spokeswoman Emma Watson has noted (2014), quiet, thoughtful, and sensitive men may also be seen to lose out, appearing as lesser, inept, or unattractive, when machismo is valorized above all else (while still, no answer is given regarding challenges that remain for confident, ambitious women at 
work). Much more will be said in relation to the gender essentialism of Lean In and in higher education workplace values in the next sections.

\section{Lean In and Race, Class, and Identity}

As previously mentioned, in asking women to be confident like men to get ahead, Lean In and related assimilatory discourses of women at work promote gender essentialism, which treats women as naturally more nurturing, generous, and sensitive, and men as strong, brave, powerful, and shrewd. As an ideology it obscures or regards as unnatural those cases where women are shrewder and men are more self-sacrificing. However, as Judith Butler (1990) powerfully articulates, we perform gender rather than being born with it, against the backdrop of external assumptions and experiences. It is not illegal for boys to cry, but boys learn powerful messages, not necessarily (or only) from their parents or teachers but from the hidden curriculum of the playground and the world around them, that boys should not cry (Thorne, 1993). This is problematic in relation to gender equity, as those characteristics viewed as masculine are celebrated above traits associated with women, while they are hardly split naturally across genders in a free and equal environment. This sexism of gender expectations has been powerfully experienced by individuals with gender dysmorphia, or who undergo sex or gender changes, whose experiences reflect that gendered traits exist on a spectrum for individuals rather than as a binary set of "male” and “female” traits (Airton, 2009; Feinberg, 2012). Their experiences also serve to enlighten those who would say that leaning in is sufficient, as those who experience the world first as a man and then as woman (or vice versa) find themselves facing two very distinct sets of expectations, and resistance to their expertise and authority based on gender (Feinberg, 2012; Barres, 2006). Assimilating in historically male-dominated spaces is thus a partial solution at best, as gender inequity at work is not only about individual's behaviors, but also about ascribed identities.

However, the discussion of gender essentialism thus far has been additionally restricted by its framing from within white, western cultural expectations, while the variety of norms and values within and between cultural communities related to men and women's behaviors also complicate things. Race, class, gender, and other identity categories intersect with each other in people's lived experiences (Jackson, 2014b), such that upper-middle class and wealthy white women do not share 
parallel experiences with other women across race and class. Within other communities, gender norms are often different than in the contexts Sandberg is familiar in, wherein white, heterosexual, upper-middle class and wealthy Christians, with no major physical or mental disabilities or impairments, are advantaged over others as normal. As bell hooks (2013) notes, Sandberg does not discuss race or class substantively (though she acknowledges that women of color face worse pay gaps than white women in corporate America), but most of her anecdotes and knowledge clearly stem from contexts dominated by wealthy white men.

Similar issues have been explored by many scholars in the past in reading from the large and diverse body of academic work on feminism. As Chandra Talpade Mohanty (1984) has written from a postcolonial perspective on the field, when all of people's experiences around the world are put into a dichotomy of woman and man, woman becomes a signifier of oppression, disadvantage, and powerlessness. As she writes, “the discursively consensual homogeneity of 'women' as a group is mistaken for the historically specific material reality of groups of women” around the world, based on the assumption that all women share the experiences of western women (p. 262). Mohanty contends that this essentialization unwittingly produces a status of victimhood upon non-western women, before looking at the realities of their experiences, under the assumption that all women have the same experiences. At the same time, intergroup historical relations have also framed "western" as powerful over the colonial subject, so that women in different racial and ethnic groups face a racial oppression and status that distances them in identity from western women, while uniting them at the same time with men from their community. As hooks notes in the American context, "when the women's movement raised the issue of sexist oppression, we argued that sexism was insignificant in light of the harsher, more brutal reality of racism” (1990, p. 1). Though girls and women doubtlessly face victimization across societies and communities, their struggles are not equivalent across race and ethnicity (Suleri, 1992).

Within societies (including the United States), gender norms and expectations are different across races and ethnicities, and racism and ethnocentrism's place in this differentiation as a dynamic historical process additionally gives pause to women of color in joining a universalist, essentializing western feminism, or leaning in. For instance, hooks reflects that "white feminists tended to 
romanticize the black female experience,” viewing black women as normally or ideally stronger, more sassy and assertive, and louder than white women (1990, p. 6). Yet individualization and assimilatory discourses of Lean In and higher education, supported by white women scholars and thinkers, can nonetheless neglect how women of color are negatively impacted by expectations also based on race and racialized notions of gender. Presumptions of sameness across race and dismissals or neglect of racialized gender identities extends further to contemporary feminist discussions of voice and inclusion, wherein women of color in academic (and other) spaces report feeling pressure to extensively share themselves and collaborate sensitively with white women, by implication educating white women about their own views and challenges, instead of engaging in work they may see as more vital to themselves and their communities (Lugones \& Spelman, 1983). In such contexts women of color may also experience a double-bind of guilt and pressure from their home community or family, for apparently changing their culture and outlook, if they substantively assimilate in personality or identity to be comprehensible and accepted according to white (or white woman) norms.

In higher education, research demonstrates that in contrast with white women, women of color (and particularly black women) face pressure to justify their presence-being assertive and authoritative, for instance—-without appearing “too" emotional, passionate, hostile, or angry. Unlike white women, they are stereotyped as "affirmative action hires," eyed with suspicion by security guards, and pressured by well-meaning but racially-anxious colleagues, to share more about their personal lives warmly and openly, and portray more consistently (in comparison with expectations for men and whites) a peaceful, pleasant, harmonious facade, in order to be seen as aligned with professional norms of higher education (Gutierrez y Muhs, Niemann, Gonzales \& Harris, 2012; see also Davis, Reynolds \& Jones, 2011). More so than white women, women of color are thus caught between appearing overly passionate when they are committed, confident, and driven; or incompetent, when they are silent, in some cases paralyzed, by the schizophrenic requirements of presentation and performance faced.

Thus when asked to lean in, notions of (white) “women’s” deficiencies of confidence intermesh with notions of deficiencies of white normalcy in the experiences of professional women of 
color in the higher education workplace, creating a lose-lose situation. White women may face a stereotype of quietness and insecurity that is different from the stereotype of women of color (particularly black and Latino women) as boisterous, vocal, and unabashed. In this context, leaning in is far less helpful to women of color than it is to white women, and reflects not just expectations to support a male-dominated workplace (as discussed in the previous section), but also a whitedominated workplace. Indeed, while white women may be counseled in developing teaching and networking skills to lean in, as Sandberg recommends, women of color are more likely to experience tips about their tone according to studies, implying rather that it is better for them to lean out in terms of assertiveness, confidence, and drive, to succeed as women of color in higher education (Rodgers \& Cudjoe, 2013).

Social class is another factor related to inequity in society and education that intersects with gender and race. The significance of class is often overlooked in liberal democratic societies and other cultural contexts that idealize meritocracy as having eliminated oppressive material inequality particularly among racially privileged groups (for example, whites in the United States and Europe). Additionally, class as a marker of difference is less clear and visible, while many would say that class is fluid, such that earning a doctorate would effectively move a person from working class to middle class, resulting then in a relatively class-equal higher education workplace (Jackson, 2014b). However, as with race and gender, family socioeconomic background is also seen to correlate with educational attainment and employment in higher education, and with the prestige of an institution and an individual's position within it (Kniffin, 2007).

At the individual level, first-generation and working-class academics, including white women and many women of color, find that they must learn to adapt to educational expectations, particularly higher education norms in the United States today, in ways that can be stifling of their personal identity. For instance, one may have to decrease their passionate, emotional communication and sense of humor. Vocabulary, accent, and dialect may become reframed as markers of deficiency that nonmiddle-class academics should hide (Wilson, 2006). Because the norms and pathways through higher education are indicated to less economically advantaged students in sparse, invaluable snippets of advice from professors which are later discovered to be common knowledge to better-off peers, a 
sense of imposter syndrome can be enhanced through professional development, related to a deepening awareness of known unknowns about how one is received as potentially deficient by peers and colleagues (Selman-Killingbeck, 2006). As previously mentioned in relation to racialized identity, women academics from disadvantaged economic backgrounds can also feel a sense of loss and pressure at the same time from friends and family back home, who do not understand or appreciate the norms and realities of higher education.

Many other identities beyond gender, race, and class impact higher education, including sexual orientation, size, age, ability, language, and religion, to name a few. Yet leaning in and related discourses which promote individualization of inequality and assimilation to the status quo speak specifically to skills and traits desired or most effective for white, able, heteronormative, middle-class and elite-class women in western, white, male dominated professional settings (Fitzgerald, 2014). Instead of encouraging women to lean in to get ahead, higher education leaders and managers (among others) should be aware of the intersectionality of identity and the different pressures and norms women face across categories of social difference. They should also be aware that not all of these categories are visible, such as family or language background, class, or religion—or easily reduced, as women of color or lesbians (for example) are also hardly monolithic categories, but reflect a spectrum of experiences and intersections of identity with other markers, such as language, class, and so on (i.e., a black lesbian may not have the same experiences and sense of identity developed as a white lesbian, and a wealthy black person will not necessarily identify with poor black people). As identity is dialogically developed, we must not stereotype by gender, race, and so on in higher education, if we wish to empower all, rather than further victimize by labeling as deficient those facing various double-binds in attempting to assimilate to dominant race, class, or gender norms of the context.

\section{Leaning Out Worldwide}

As has been alluded to in the previous sections, the discourse of leaning in is also difficult to meaningfully translate across national contexts, despite the globalization of the Lean In movement. In the first place, the American corporate culture inspiring Lean In is rather uniquely framed by an optimistic, can-do, positive psychology-influenced view of the world, that can be seen to undergird 
Sandberg's account of corporate workplace and professional values. As Barbara Ehrenreich notes (2010; 2006), the United States has a unique history of promoting individualism and positive thinking about work as keys to professional and personal success. One should smile, focus on possibility, and demonstrate forward-thinking devotion and commitment to the workplace in order to succeed, not just in Sandberg's text but in dominant mainstream thought in the society more generally. In United States religion, health care, and corporate culture, Ehrenreich observes (2006; 2010) how blame is normally put upon oneself for such things as not surviving breast cancer, being laid off due to corporate restructuring, or failing to get a good job in a bad economy, as a result of this mentality. One particular example of this is the popularity of Who Moved My Cheese? (Johnson, 1998) during the economic crisis of the 1980s. This book suggested that it did little good to think about the external reality (Sandberg’s “egg”) when one could focus on his or her own attitude. The book was beloved by corporations laying off workers due to its deflecting attention from corporate actors or corporate restructuring, upon oneself as an individual.

As Ehrenreich (2010) notes, before the financial crisis of 2008, people who drew attention to risks and limitations in the U.S. corporate workplace were regarded as overly pessimistic. Some were fired due to sounding procedural alarms as their managers (many of whom stood to benefit regardless of outcomes, in contrast with the American public and lower-level workers) regarded them as insufficiently optimistic. Thus, the expectation of a smiling face can be seen as exploitive to workers. From the perspective of knowledge-based and evidence-based organizations, managers who prefer ambitious and fearless workers over more cautious and conscientious ones risk ignoring evidence or precluding a balanced assessment of choices and opportunities ahead. The evidence underlying claims about the powers of positive thinking for health care and professional success is inadequate; yet some people benefit as motivational speakers and coaches, and through selling crystals and related goods, with the use of persuasive pseudoscience mixed with a handful of proper, though inconclusive, findings from research (Ehrenreich, 2010).

Regardless of the merits and demerits of the workplace values of corporate America, smiling, projecting confidence in light of uncertainty, and boasting of oneself are not viewed as so key to personal and professional success in many other contexts (see for instance, Watson, 2012; Martin \& 
Chaney, 2012). In the first place, while a deficiency mentality regarding gender equality reigns in the United States, where feminism is typically understood as seeing men and women's potentials as equal, expectations about gender relations and other interpersonal relationship dynamics differ across countries. Thus, women in different countries, such as in Africa or Asia, may not be similarly rewarded for acting more like male counterparts, but may be understood to have access to gendered characteristics and expressions inaccessible to men to help them in the workplace. Of course, as all gendered expectations create a double-edged sword, this does not imply that things are better for women in these alternative contexts. However, this demonstrates that different conceptions of men and women's equivalency are normalized across societies, which makes an assimilatory, deficiency model of gender equality less helpful in societies where women and men are not expected to increasingly act in similar ways.

Additionally, hierarchy can matter much more in non-American professional contexts to indicating and being seen as possessing competence or excellence. In many Asian and African contexts, the need to allow senior colleagues to "save face," for instance, can limit the value of a young or junior colleague, male or female, chipping in feedback nonchalantly in a meeting, with optimistic or ambitious thoughts and recommendations (Jackson, 2013). Furthermore, overt expressions of ambition by young men or women may be a liability in high-context cultures. This does not mean that junior men and women professionals should act the same way as each other in higher education outside the United States, as gender relations may also be viewed in a nuanced way in professional settings across cultures. But it does mean that workplace norms and workplace relations and identities vary across cultural contexts, ultimately making leaning in a liability in some international environments.

Finally, at a simpler, incidental level, norms around smiling, emotional expressions, and behaviors representing confidence, such as making eye contact and physical leaning in, can vary across cultural and social contexts (Watson, 2006). Productive manners for workplace communication and professional development across cultures should not be unwittingly reduced to one kind that is modeled arbitrarily after the American corporate world. Thus the American model should not be taken as superior, ideal, or worth assimilating to, across environments where contrasting, legitimate 
and culturally appropriate ways of expressing authority, commitment, responsibility, and other workplace virtues may differ, and where acts like smiling and leaning in may simply not send the same messages that they do in the United States. By implication, higher education leaders should not use Lean In as a prescriptive guide to enhance gender equity across international contexts. Leaning in is not merely pragmatic professional advice for women around the world. Instead, it should be viewed as an artefact of a time, place, and culture: that of the white, middle-class and elite corporate United States in the early-twentieth century. As such its utility is questionable in alternative cultural contexts. As an American trend, it should be examined as indicative of national norms within a particular national subculture, which may be at odds with those of higher education cultures in other places.

Given internationalization of education, it may be useful and productive across educational contexts to examine and explore Lean In discursively. As Aiston (2011) observes, the "cult of individualism" certainly echoes from the book to higher education experiences internationally. Its deconstruction could thus also serve to critically interrogate related trends outside the United States. Individualization manifested in Lean In and higher education workplaces also can be seen to interrelate with neoliberalization of education worldwide, as the United States and other western countries are powerful global actors in education today. Yet, as educational practice must reflect local needs rather than global values to benefit communities, leaning in and embracing American workplace culture should not be endorsed wholesale, to the exclusion of more potentially effective and appropriate programs for enhancing gender equality in specific contexts. Indeed, context counts, despite the persuasive power of individualization reflected in Lean In, neoliberalism, and related discourses in higher education; it should not be the duty of the disadvantaged (by gender, race, culture...) to change for equity to occur. Such a paradoxical demand, that leaves the status quo untouched, cannot change unequal conditions into equal ones. Rather than asking women to lean in around the world, those dedicated to equity in higher education in positions of power should instead lean out worldwide, ceasing to promote assimilation and in its place valuing diversity through acts of recognition and promotion of pluralism.

\section{Conclusion}


This essay has used the increasingly global Lean In gender equality discourse or movement as an example of the new nonthreatening feminism of the early twenty-first century. It has critically scrutinized its resonance and utility in higher education from an international and postcolonial perspective, considering women across identities and experiences worldwide. Three major critiques were explored in relation to higher education. The first was that Lean In relies on a deficiency model to be unthreatening to the status quo, wherein women must try to assimilate to contemporary norms: in Sandberg's case, of American corporations, and in higher education, of individualist meritocracy. I argued against such orientations that women cannot merely assimilate to workplace norms of either sphere effectively to achieve greater equity, because the expectations women face in those environments are different from those faced by men. Furthermore, the value of traditionally masculine traits is also questionable. A more balanced expression of workplace values and virtues should be supported in higher education, while gender expectations based on a binary view should be problematized more generally. Leaning in is therefore problematic advice, even for white, wealthy women in western societies, whose challenges to success go beyond their personal attitudes, by a structuralist analysis of the situation (Morley, 2014).

The second and third critiques focused on the perspectives of women of color and other women from different subcultures, as well as from within international or cross-cultural professional and higher education environments. For women of color and from disadvantaged family backgrounds (among others), adapting to cultural norms of white middle-class and elite society may carry significant risks to personal and professional wellbeing beyond those faced by white, wealthy counterparts. These include alienation from one's communities and the neglect of a more holistic view of their struggles for equity in society. Furthermore, women of color are also often expected to act differently from white women in the United States, while an intersectional understanding of identity implies we must see all identities as nuanced and dialogically constructed across categories of race, class, gender, language, religion, age, ability, and so on. From an international perspective, norms are also different across countries, with regard to both cross-gender professional relations and workplace communication values. This implies that leaning in is in some important ways a cultural and American phenomenon, and should not be held as a universalistic requirement for enhancing 
gender equity across diverse societies, despite its clear resonance with higher education environments around the world today. Instead, educators and women in different societies will profit more from considering their own communities and contexts' work values and professional norms in a balanced, more holistic and structural way, in order to develop woman professionals and enhance gender equality and equity in the future. In sum, leaning in may sound easy—but whether it is worth doing for many women in this world is questionable.

Higher education actors, including both men and women, thus might consider leaning out away from discourses of individualization, assimilationism, and acceptance of structurally inequitable status quos. Instead of framing difference as deficiency in historically (and contemporarily) maledominated and white-dominated spaces, diverse professional skills and characteristics should be explored as possible assets that different individuals, groups, and communities may bring to higher education environments in a variety of ways. Rather than expect those victimized by external inequities and biased professional norms to adapt, “leaning out” can enable all actors and communities in higher education to further develop to enhance conditions for greater inclusivity. As neoliberalism and internationalism become engrained features of higher education aspirations around the world, by leaning out higher education leaders can raise awareness of pitfalls of individualization and recognize the potential of alternative models for development not marked primarily by aggression, competition, and individualism, but by other important academic values, of diversity, pluralism, toleration, and open-mindedness. Thus Lean In can be instructive not just as a how-to guide, but as a how-not-to guide, as higher education leaders can explore ways to change conditions to enable equity, rather than continually blame disadvantaged players for unequal outcomes. 


\section{References}

Airton, L. (2009). Untangling “gender diversity”: Genderism and its discontents (i.e., everyone). Diversity and Multiculturalism: A Reader, ed. S. R. Steinberg (pp. 223-246). New York: Peter Lang.

Aiston, S. J. (2011). Equality, justice and gender: Barriers to the ethical university for women. Ethics and Education 6: 279-291.

Barres, B.A. (2006). Does gender matter? Nature 422: 133-136.

Biernat, M., Tocci, M. J., \& J. C. Williams. (2012). The language of performance evaluations: Gender-based shifts in content and consistency of judgment. Social Psychological and Personality Science, 3 (2): 186-192.

Boring, A., Ottoboni, K., \& P. Stark. (2016). Student evaluations of teaching (mostly) do not measure teaching effectiveness. ScienceOpen Research (in press).

Bowles, H. R., Babcock, L., \& L. Lai. (2007). Social incentives for gender differences in the propensity to initiate negotiations: Sometimes it does hurt to ask. Organizational Behavior and Human Decision Processes 103(1): 84-103.

Butler, J. (1990). Gender Trouble: Feminism and the Subversion of Identity. New York: Routledge.

Cain, S. (2013). Quiet: The Power of Introverts in a World that Can't Stop Talking. New York: Broadway.

Curtis, J. W. (2010). Faculty salary equity: Still a gender gap? On Campus With Women 39 (1).

Davis, D.J., Reynolds, R., \& T.B. Jones. (2011). Promoting the inclusion of tenure earning black women in academe: Lessons for leaders in education. Journal of Educational Administration and Policy, 5 (1). pp. 28-41.

Ehrenreich, B. (2010). Bright-Sided: How Positive Thinking is Undermining America. New York: Picador.

Ehrenreich, B. (2006). Bait and Switch: The Futile Pursuit of the American Dream. New York: Hult. Feinberg, L. (2012). Stone Butch Blues. ReadHowYouWant.

Fitzgerald, T. (2014). Women Leaders in Higher Education: Shattering the Myths. Abingdon: Routledge. 
Flaherty, C. (2014). Her side of the story. Inside Higher Ed, March 17.

Fox, M. F., \& C. Colatrella. (2006). Participation, performance, and advancement of women in academic science and engineering: What is at issue and why. The Journal of Technology Transfer 31 (3): 377-386.

Gutierrez y Muhs, G., Niemann, Y. F., Gonzales, C.G., \& A.P. Harris. (2012). Presumed Incompetent: The Intersections of Race and Class for Women in Academia. Logan: Utah State University Press.

Heilman, M. E., \& T. G. Okimoto. (2007). Why are women penalized for success at male tasks? The implied communality deficit. Journal of Applied Psychology 92 (1): 81-92.

hooks, b. (2013). Dig deep: Beyond lean in. The Feminist Wire, October 28.

hooks, b. (1990). Ain’t I A Woman: Black Women and Feminism. London: Pluto Press.

Hytten, K., \& Warren, J. (2003). Engaging whiteness: How racial power gets reified in education. International Journal of Qualitative Studies in Education 16(1): 65-89.

Jackson, L. (2014a). Muslims and Islam in US Education: Reconsidering Multiculturalism. New York: London.

Jackson, L. (2014b). Comparing race, class and gender. Comparative Education Research: Approaches and Methods, eds. M. Bray, B. Adamson, and M. Mason (pp. 195-220). Hong Kong: Comparative Education Research Centre/Springer.

Jackson, L. (2013). They don’t not want babies: globalizing philosophy of education and the social imaginary of international development. Philosophy of Education Yearbook 2013, ed. C. Mayo (pp. 353-361). Urbana: Philosophy of Education Society.

Johnson, S. (1998). Who Moved My Cheese? An Amazing Way to Deal with Change in Your Work and Life. New York: G.P. Putnam’s Sons.

Kay, K., \& C. Shipman. (2014). The Confidence Code: The Science and Art of Self-Assurance-What Women Should Know. New York: HarperBusiness.

Kniffin, K. M. (2007). Accessibility to the PhD and professoriate for first-generation college graduates: Review and implications for students, faculty, and campus policies. American Academic, 3. 
Lean In. (2016). Tips for men at home. Lean In, http://leanin.org/tips/home/, accessed Jan. 152016.

Lugones, M. C., \& E. V. Spelman. (1983). Have we got a theory for you! Feminist theory, cultural imperialism and the demand for “the woman’s voice.” Women’s Studies International Forum 6 (6): 573-581.

Macnell, L., Driscoll, A., \& A.N. Hunt. (2014). What's in a name: Exposing gender bias in student ratings of teaching. Innovative Higher Education, December.

Martin, J. S., \& L.H. Chaney. (2012). Global Business Etiquette: A Guide to International Communication and Customs. Santa Barbara: ABC-CLIO.

Misra, J., Lundquist, J. H., Holmes, E., \& S. Agiomavritis. (2011). The ivory ceiling of service work. Academe, February.

Mohanty, C. T. (1984/1995). Under western eyes: Feminist scholarship and colonial discourses. Boundary, extracted in The Post-colonial Studies Reader, eds. B. Ashcroft, G. Griffiths, \& H. Tiffin (pp. 259-263). New York: Routledge

Morley, L. (2014). Lost leaders: women in the global academy. Higher Education Research and Development, 33 (1). pp. 114-128.

Poehler, A. (2015). Amy Poehler’s Smart Girls, at http://amysmartgirls.com/about-us/.

Rodgers, S.T., \& T. Cudjoe. (2013). Images of Black leadership and mentoring in higher education: Personal narratives from faculty and staff. Journal of Research Initiatives, 1 (1): 1-12.

Sandberg, Sheryl. (2013). Lean in: Women, Work and the Will to Lead. New York: Knopf.

Selman-Killingbeck, D. (2006). Trash in the ivory tower. In Reflections from the Wrong Side of the Tracks: Class, Identity, and the Working Class Experience in Academe, eds. C. V. Samarco \& S. L. Muzatti. Lanham: Rowman \& Littlefield.

Shevinsky, E. (2015). Lean Out: The Struggle for Gender Equality in Tech and Start-up Culture. Portland: OR Books.

Suleri, S. (1992). Woman skin deep: Feminism and the postcolonial condition. Critical Inquiry, 18(4). Thorne, B. (1993). Gender Play: Girls and Boys in School. Rutgers University Press. Watson, E. (2014). Speech for He-For-She. United Nations Headquarters, New York. Watson, J. L. (2006). McDonald's in Hong Kong. In Golden Arches East: McDonald's in East Asia, 
ed. J. L. Watson. Stanford: Stanford University Press.

Wilson, J. L. (2006). Examining the dissonance. In Reflections from the Wrong Side of the Tracks: Class, Identity, and the Working Class Experience in Academe, eds. C. V. Samarco \& S. L. Muzatti. Lanham: Rowman \& Littlefield. 